\title{
PROJETOS EM MÍDIA-EDUCAÇÃO NA REDE MUNICIPAL DE PORTO ALEGRE: A EDUCOMUNICAÇÃO COMO DISCURSO E A PEDAGOGIA INSTRUMENTAL DE USO DOS MEIOS COMO PRÁTICA
}

\author{
PROJECTS IN MEDIA EDUCATION IN \\ PUBLIC SCHOOLS OF PORTO ALEGRE: \\ EDUCOMMUNICATION AS DISCOURSE \\ AND INSTRUMENTAL PEDAGOGY \\ OF MEDIUMS USED AS PRACTICE
}

Rodrigo Ramos

Resumo: O presente artigo analisa os princípios curriculares de um projeto de mídia-educação desenvolvido em uma escola municipal de Porto Alegre, o qual é amparado pelo Projeto Alunos em Rede - Mídias Escolares, da Secretaria Municipal de Educação (SMED). Os dados e análises apresentados foram obtidos no desenvolvimento de uma pesquisa, de cunho etnográfico, realizada em 2012. Discute-se, inicialmente, o campo da mídia-educação e, depois, o conceito de educomunicação e sua relação com a tradição crítica, visto que o termo é um dos pilares conceituais da SMED. Em seguida, apresentam-se alguns princípios curriculares em mídia-educação crítica no contexto internacional para, depois, discutir algumas aproximações e afastamentos que o projeto, no contexto de sala de aula, opera no que diz respeito às propostas críticas em educação.

Palavras-chave: Educomunicação. Mídia-educação. Tradição crítica. Currículo. 


\begin{abstract}
This article analyzes the curricular principles of a media education project developed in a public school of Porto Alegre, which is supported by the Project "Students in Network - Media School", by the Municipal Education Secretariat (SMED). The data and analyses presented here were obtained through ethnographic research conducted in 2012. The field of media education is presented, at first, then, the concept of educommunication and its relation to critical tradition is examined, since the term is one of SMED conceptual supports. Afterwards, some curricular principles in critical media education in the international context are presented and finally a discussion of the mechanics of an experience in the context of the classroom is offered, relating it to the critical tradition in education.
\end{abstract}

Keywords: Educommunication. Media education. Critical tradition. Curriculum. 


\section{Introdução}

A “revolução" tecnológica intensificada a partir dos anos de 1990 tem provocado mudanças na qualidade de interação entre os sujeitos e na forma de circulação de saberes. A internet, especialmente, tensiona a lógica de produção de mensagens, em que todos os que dela têm acesso podem produzir mensagens e veiculá-las para centenas ou milhares de pessoas. Nesse contexto de transformações, qualificar-se tecnologicamente e comunicar-se de forma competente passa a ser não só um discurso mercadológico predominante, mas principalmente um imperativo educacional por qualificação profissional e inclusão digital. Programas para implementação de laboratórios de informática nas escolas públicas, como o ProInfo, do Ministério da Educação, e outros projetos de inclusão digital, como os telecentros comunitários, promovidos pelo Ministério das Comunicações em parceria com estados e municípios, são implementados em todo o país.

Além de programas governamentais de acessibilidade tecnológica, projetos de comunicação e educação começam a ganhar espaço nas políticas públicas em todo o país, alguns dos quais são desenvolvidos em parceria com organismos internacionais e com organizações não-governamentais (ONGs), como, por exemplo: Educom. rádio, projeto desenvolvido pelas secretarias de educação de São Paulo e Mato Grosso do Sul em parceria com a USP; Mudando sua escola, mudando sua comunidade, melhorando o mundo, projeto desenvolvido na rede de ensino de São Paulo, Rio de Janeiro, Belo Horizonte, Salvador e Fortaleza, promovido pela UNICEF, ONGs e secretarias de educação (TOTH, 2012). Em Porto Alegre, o projeto Alunos em Rede - Mídias Escolares é implementado desde 2008 na rede municipal de ensino, o qual é foco de análise neste artigo. 
Na próxima seção, apresento um breve panorama sobre a interface comunicação-educação. Depois, reflito sobre um novo conceito e campo epistemológico chamado, no Brasil, de educomunicação, o qual está intrinsecamente atrelado à pedagogia crítica latino-americana. Em seguida, apresento o projeto Alunos em Rede - Mídias Escolares, que é desenvolvido pela secretaria municipal de educação de Porto Alegre, e analiso, a partir de um estudo de caso de cunho etnográfico, a experiência do projeto em uma escola da rede municipal.

\section{UM breve histórico sobre a interface entre comunicação e educação}

A partir do século XXI, com a disseminação das chamadas novas tecnologias e com o desenvolvimento de pesquisas sobre educação a distância, os estudos e projetos relacionados à interface educação/comunicação ganhou força e novos rumos. Para discutir as tendências atuais sobre a questão, faço, primeiramente, um breve histórico sobre o tema.

A partir da invenção da imprensa, o jornal ocupou o espaço de mídia privilegiada na escola. Em 1694, por exemplo, o então reitor da Universidade de Paris defendia a escrita tipográfica como uma forma de aperfeiçoar a ortografia (CAPRINO, 2008). No final do século XIX,

[...] o diretor das escolas públicas de Salem, no Missouri, defendia a utilização dos jornais em sala de aula. Sua pedagogia baseava-se na distribuição diária de jornais para os alunos, seguida posteriormente por uma conversa sobre 
PROJETOS EM MÍDIA-EDUCAÇÃO NA REDE MUNICIPAL DE PORTO ALEGRE:

o que eles haviam lido (CAPRINO, 2008, p. 3 apud GONNET, 2004, p. 41).

No Brasil, a distribuição de jornais a escolas também foi um empreendimento realizado pelos Jornais Zero Hora, em 1980, por meio do projeto "Zero Hora na sala de aula", e pelo jornal O Globo, em 1982, no Rio de Janeiro, por meio do projeto "Quem lê jornal sabe mais" (idem, p. 7). Embora esses projetos estejam muito mais ligados à formação de um público leitor do que exatamente a um projeto de educação-comunicação, eles são exemplos de uso pedagógico dos meios de comunicação na escola.

No entanto, é nos trabalhos do pedagogo Celéstin Freinet - precursor da ideia de autogestão e da escola/pedagogia ativa - que é iniciada uma reflexão e sistematização de uso da imprensa na escola. ${ }^{1}$ A imprensa escolar, então, passa a ser o centro do processo educativo e é por meio dela que o conhecimento escolar é produzido, ensinado e aprendido. As ideias de Freinet ultrapassam os muros da escola e influenciam intelectuais, educadores e comunicadores sociais e populares do mundo todo. Nesse sentido, cabe mencionar que a relação entre comunicação e educação está presente também no contexto dos movimentos sociais, e é pauta dos estudos em comunicação comunitária e alternativa (PERUZZO, 2007; PAIVA, 2007; CARNICEL, 2005, entre outros). Nesse contexto, Mario Kaplún é considerado um dos ícones na instituição de práticas educativas por meio das mídias, sobretudo pela rádio.

Comunicador, intelectual e educador, Kaplún iniciou sua carreira aos 19 anos como radialista e, depois, passou a ser roteirista de televisão ao mesmo tempo em que refletia sobre a mídia e sociedade. Inspirado nas ideias de Paulo Freire e de Celestín Freinet, começou a desenvolver projetos de comunicação popular e 
de educação para a mídia na Argentina, Venezuela e no Uruguai, voltando-se às comunidades populares, sobretudo as comunidades campesinas (KAPLÚN, 2005). Entre seus trabalhos de comunicação e educação está, inicialmente, o que se convencionou chamar de mídia educativa, com produção de programas educativos pela grande mídia².

Depois, voltando-se às comunidades de base, o educador/comunicador começa seu trabalho "revolucionário". Entre as primeiras iniciativas, está o "Cassete Fórum”, que consistia em um

\footnotetext{
[...] sistema de comunicação para a promoção comunitária e a educação de adultos, colocado a serviço de organizações populares - rurais e urbanas -, centrais cooperativas, centros de educação popular, programas de educação a distância, etc. (KAPLÚN, 1988, p. 9).
}

O método consistia na gravação de uma fita cassete pelas lideranças de determinado grupo social para registrar as demandas do movimento. As filiais escutavam e gravavam suas opiniões e dificuldades. A fita voltava para o primeiro grupo, e assim sucessivamente. Segundo Gabriel Kaplún, filho de Mario, “[...] el Casete Foro ponía su acento em la posibilidad de revertir la unidirecionalidad comunicacional y recuperar el sentido dialógico de la comunicación, frente al paradigma dominante informacional y transmisor." (KAPLÚN, 2005, p. 40).

Outro marco importante para pensar a relação entre comunicação e educação é o pensamento de Paulo Freire, que, como já vimos, influenciou Kaplún nas suas experiências pela América Latina. Freire é uma das referências em educação popular e suas reflexões sobre a pedagogia do oprimido e dialogicidade perpassam muitas das ações relacionadas à comunicação comunitária. 
A partir dos anos 2000, percebe-se um ressurgimento da comunicação comunitária e, mais especificamente, da comunicação no espaço escolar devido à proliferação das novas tecnologias digitais. Além disso, políticas públicas começam a garantir o acesso à informação e à produção de mídia por meio de oficinas. Entre 2001 e 2008, segundo levantamento de Laura Tresca (2008), as seguintes capitais tinham alguma política relacionada à comunicação comunitária e educação para a comunicação: Curitiba, Fortaleza, Goiânia, João Pessoa, Macapá, Porto Alegre, Recife, Salvador e São Paulo.

No âmbito escolar, em São Paulo, a instituição da Lei n. 13.941, de 28 de dezembro de 2004, cria o Programa EDUCOM - Educomunicação pelas ondas do rádio, implementada com assessoria do Núcleo de Comunicação e Educação (NCE) da Escola de Comunicações e Artes da Universidade de São Paulo (ECA-USP) no período de 2001 a 2004. Essa mesma experiência foi desenvolvida em Mato Grosso entre 2006 e 2007. Em Porto Alegre, há o projeto Alunos em Rede, implementado desde 2008 na rede municipal de ensino. Outra iniciativa que merece menção é o projeto de educação integral Mais Educação, que prevê, entre as atividades a serem realizadas, um macrocampo denominado educomunicação (MEC, [s.d.]). Além dessas iniciativas, o Ministério da Educação e Cultura (MEC) publica a Portaria n. 971, em 2009, que institui o Programa Ensino Médio Inovador (ProEMI), o qual tem como objetivo apoiar ações de melhoria na qualidade do ensino médio não profissionalizante, incentivando reestruturações e inovações curriculares por iniciativa das escolas públicas. Entre os eixos orientadores da reestruturação e inovação curricular está também o macrocampo educomunicação e uso de mídias. Segundo o documento: 
Este macrocampo deverá desenvolver os processos relacionados à educomunicação e as ações deverão orientar e propor vivências em espaços de atuação que permitam ao jovem acesso às diferentes mídias e tecnologias da informação e da comunicação ampliando a compreensão de métodos, dinâmicas e técnicas. As atividades deverão possibilitar a criação de condições para a utilização dos instrumentos e ferramentas disponíveis, das formas e possibilidades de comunicação e de processos criativos, assim como viabilizar a reflexão sobre o uso crítico das diversas tecnologias em diferentes espaços do convívio social (fanzine, informática e tecnologia da Informação, rádio escolar, jornal escolar, histórias em quadrinhos, fotografia, vídeos, dentre outros). As atividades desenvolvidas neste macrocampo poderão estar articuladas a outros macrocampos e ações interdisciplinares da escola. (MEC, 2011, p. 15).

O que se pode perceber com as atuais iniciativas é a inserção, de forma institucional, do campo comunicação e do uso das mídias como um elemento fundamental ou ferramenta complementar à educação e às políticas públicas. Além disso, chama a atenção o uso do neologismo educomunicação, fruto das pressões de intelectuais e pesquisadores da área no âmbito dos agenciamentos políticos.

\section{A educomunicação}

O termo educomunicação é um neologismo que vem sendo utilizado por inúmeros intelectuais que atuam no campo da comunicação e educação. Foi alcunhado por um grupo bastante presente no cenário nacional: o Núcleo de Comunicação e Educação (NCE) da Escola de Comunicações e Artes da Universidade 
de São Paulo (ECA-USP). Liderado pelo professor Ismar Soares, o NCE adotou o termo educomunicação a partir de uma investigação sobre o trabalho realizado por diferentes pesquisadores do mundo que se dedicavam a compreender as interfaces entre comunicação e educação, conforme esclarece o excerto a seguir:

O que descobrimos com a pesquisa foi que a inter-relação entre a Comunicação Social e a Educação havia alcançado densidade própria, superando a fragmentação das ações ora denominadas como 'educação para os meios', 'tecnologia educacional', ou, ainda, 'comunicação educativa', afigurando-se ao contrário, como um campo específico de intervenção social capaz de aproximar e dar sentido a um conjunto de tais ações. Para designar esta realidade, escolhemos o neologismo 'educomunicação' - usado por Kaplún como sinônimo de 'educación a los medios' - dando novo significado à palavra para designar a radical transversalidade da comunicação nos processos educativos levada a cabo, há pelo menos 40 anos, por inúmeros centros de comunicação e documentação popular, por organizações não governamentais voltadas para a comunicação alternativa, bem como por indivíduos engajados em programas que possibilitaram ao homem mais agilidade e maior abrangência na compreensão da relação entre a prática comunicativa e a prática educativa. (SOARES, 2006, p. 176).

É importante perceber a influência a produção do referido grupo entre os intelectuais e gestores na formulação de políticas públicas. Os documentos legais, como os Parâmetros Curriculares Nacionais, relacionados ao trabalho de linguagem por meio de recursos midiáticos, bem como projetos de educação e comunicação, recebiam diferentes denominações antes dos anos 2000. No entanto, a partir da atuação do NCE-USP, muitos pesquisadores começaram, igualmente, a adotar o termo educomunicação para referir-se ao que antes denominavam "educação/comunicação" ou 
"mídia e educação". Para deixar, então, mais claro o que o grupo entende por educomunicação, cabe trazer suas definições, que complementam as ideias do excerto precedente. Embora longo, a citação está justificada devido a influência da definição que está pautando o léxico da área, o qual baliza discursivamente a construção do projeto de mídia-educação de Porto Alegre, que será apresentado neste artigo. Segundo o NCE-USP, a educomunicação é definida como

[...] um conjunto das ações destinadas a: 1 - integrar às práticas educativas o estudo sistemático dos sistemas de comunicação (cumprir o que solicita os PCNs no que diz respeito a observar como os meios de comunicação agem na sociedade e buscar formas de colaborar com nossos alunos para conviverem com eles de forma positiva, sem se deixarem manipular. Esta é a razão de tantas palestras sobre a comunicação e suas linguagens); 2 - criar e fortalecer ecossistemas comunicativos em espaços educativos (o que significa criar e rever as relações de comunicação na escola, entre direção, professores e alunos, bem como da escola para com a comunidade, criando sempre ambientes abertos e democráticos. Muitas das dinâmicas adotadas no Educom apontam para as contradições das formas autoritárias de comunicação); 3 - melhorar o coeficiente expressivo e comunicativo das ações educativas (Para tanto, incluímos o rádio como recurso privilegiado, tanto como facilitador no processo de aprendizagem, quanto como recurso de expressão para alunos, professores e membros da comunidade). (SOARES, [s.d.], p. 1).

A definição de educomunicação de acordo com os excertos, a qual tem origem nas ideias de Mario Kaplún, abrange um conjunto de ações e, portanto, está atrelada a uma proposta de prática educacional por meio e para os meios de comunicação bastante próxima às pedagogias críticas. Conforme o tem 1 do excerto precedente, a prática educomunicativa pressupõe que sejam postos em pauta os discursos pelos quais a mídia, ou as mídias, constroem o senso comum. O segundo item da proposta de definição do termo 
educomunicação, conforme pode ser lido no excerto, remete a um conjunto de ideias presentes, de forma abrangente à ideia de pedagogia crítica de Paulo Freire e também da comunicação participativa de Mario Kaplún. Esse, ao entrar em contato com a pedagogia do oprimido, faz uma analogia entre o educador e o comunicador: assim como há a educação bancária, há comunicação bancária. $\mathrm{E}$ propõe, na sua pedagogia dos/para os meios, uma comunicação (dialógica e não monológica) mais horizontal, problematizadora e democrática (KAPLÚN, 1998). O mais interessante, contudo, é que o termo educomunicação, por estar muito em voga no Brasil nas últimas décadas, reacende a discussão da educação popular e tradição crítica e do papel da comunicação nos processos educativos.

Segundo Schaun (2002), o campo educomunicativo é definido pela

[...] intervenção política e social fundamentada na experiência e na formação crítica dos processos históricos, sempre voltadas para uma perspectiva de leitura crítica dos meios de comunicação, atuando no âmbito do ensino formal e não formal." (p. 82).

É evidente, portanto, que a educomunicação nasce com pensamento crítico na América Latina e tem como objetivo a intervenção no real. Nesse aspecto, cabe mencionar a pesquisa realizada por Toth, Mertens e Makiuchi, da Universidade de Brasília, que teve como objetivo investigar a contribuição da educomunicação em novos espaços de participação social no contexto do desenvolvimento sustentável (TOTH, 2012). Os autores concluem que a educomunicação amplia a participação social e exerce papel fundamental para a democratização da informação. Cabe destacar, como forma de legitimação de um novo campo profissional, a 
criação, em 2011, da primeira Licenciatura em Educomunicação, vinculada à Escola de Comunicação e Artes da Universidade de São Paulo.

\section{Abordagens curriculares para ensino-aprendizagem em educomunicação}

A discussão sobre políticas de educação para os meios (e com os meios) tem incluído o currículo como ponto de reflexão. A revista científica ibero-americana Comunicar, por exemplo, tem publicado reflexões sobre as políticas públicas de educação midiática, e sua edição de número $32^{3}$

, publicada em 2009, apresenta uma preocupação de educadores e pesquisadores de vários países sobre a construção de um currículo que dê conta das demandas de uso das mídias. Outro exemplo é a publicação da Organização das Nações Unidas para a Educação, a Ciência e a Cultura (UNESCO, 2011) destinada à formação de professores, que estabelece orientações curriculares para uma prática pedagógica de letramento midiático.

Kellner e Share (2011, p. 316) afirmam que a mídia-educação “[...] é definida menos como um corpo determinado de conhecimento ou conjunto de habilidades, e mais como um modelo de compreensões conceituais." (ibid., p. 316). Os autores afirmam que, embora seja muito incipiente o campo da mídia-educação nos Estados Unidos, existem discussões sobre os motivos e a forma de ensiná-las. Dividiram, assim, a pedagogia da mídia em quatro abordagens: a protecionista, a de uso instrumental da mídia, a de letramento e, por fim, a leitura crítica da mídia. A protecionista 
configura-se como uma abordagem em que os expectadores, leitores e ouvintes são tratados como vítima. Nessa abordagem pedagógica, segundo os autores, há um componente crítico, mas pouco aprofundado sobre as funções que a mídia exerce na sociedade contemporânea. A segunda abordagem utiliza os recursos midiáticos apenas como ferramenta pedagógica, sem uma reflexão sobre funções entre comunicação e sociedade. Já o letramento é uma abordagem pedagógica que, ao "letrar", potencializa o uso, muitas vezes funcional, da mídia. Os autores argumentam que um trabalho de letramento não necessariamente aborda as questões problemáticas, como a distribuição desigual dos recursos midiáticos e a legitimação também desigual dos discursos com eles produzidos. A perspectiva pedagógica de leitura crítica inclui os aspectos mencionados anteriormente, mas acrescenta uma análise de crítica ideológica e discursiva sobre como a mídia constrói representações, expandindo a análise textual a fim de "[...] incluir questões do contexto social, do controle, da resistência e do prazer, e do incentivo à produção de mídia alternativa" (KELLNER; SHARE, 2011, p. 323).

Retomando a conceituação de educomunicação proposta por Soares ([s.d.]), a qual sustenta a formulação do projeto Alunos em Rede - Mídias Escolares, pode-se claramente identificar uma abordagem crítica, como já afirmado anteriormente. Ou seja, é uma abordagem que contempla o uso de mídias, o letramento, incluindo uma problematização mais aprofundada sobre as questões políticas e culturais que estão relacionadas aos meios de comunicação. No Brasil, Soares (2002) identifica as mesmas abordagens pedagógicas mencionadas por Kellner e Share (2011). Contudo, ao comparar os estudos norte-americanos e brasileiros, o autor ressalta que no mundo latino-americano, “[...] as práticas de educação para mídia estiveram tradicionalmente vinculadas a propostas de 
comunicação alternativa e aos projetos de resistência cultural dos anos 70 e 80." (SOARES, 2002, p. 21). É o que constata também Fonseca (2004) em seu mapeamento sobre as interseções entre educação e comunicação. É em virtude desse vínculo entre educação, comunicação e movimentos sociais que comumente o termo é associado à pedagogia crítica.

Orofino (2005), com base na pedagogia de Paulo Freire e na teoria das mediações de Jesús Martín-Barbero, propõe o que denomina pedagogia dos meios pautada pela participação, em oposição a uma visão funcionalista e instrumental da tecnologia. Para a pesquisadora, a pedagogia dos meios "refere-se à práxis mesma, ou seja, à intervenção no espaço escolar”. Portanto, está relacionada e atrelada a cada contexto onde é desenvolvida. No entanto, a autora sugere algumas diretrizes:

[...] a educação escolar precisa de uma perspectiva crítica para o uso das mídias que avance para além da leitura crítica dos meios e que proponha a produção criativa no próprio espaço escolar como construção de respostas sociais aos meios de comunicação de massa e que propicie modos de construção de visibilidade para as culturas locais e para as diferentes identidades socioculturais; 2) nesse sentido, a fundamentação teórica deve partir de uma teoria dos usos sociais das tecnologias e da teoria das mídias e mediações escolares; 3) A pedagogia dos meios deve estar em sintonia com um projeto político-pedagógico que se fundamente em uma perspectiva de gestão democrática da escola e da construção da cidadania. (OROFINO, 2005, p. 117).

Como fica evidente no excerto, a pedagogia dos meios deve permitir a construção de visibilidades (historicamente silenciadas), produzindo respostas sociais e, além disso, deve ser gerida numa perspectiva democrática e participativa. 
Além das abordagens curriculares em educomunicação mencionadas anteriormente, é importante destacar a proposta radical de Belloni (2005). Preocupada com os desafios da escola frente às tecnologias da informação e comunicação, em um futuro de aumento das demandas de oferta de ensino, de qualidade e de tempo, a autora propõe que

[...] a integração das tecnologias de informação e comunicação, como eixo pedagógico central, pode ser uma estratégia de grande valia, desde que a integração considere as técnicas em suas duas dimensões indissociáveis: ferramentas pedagógicas extremamente ricas e proveitosas para a melhoria e expansão do ensino; objeto de estudo complexo e multifacetado, exigindo abordagens criativas, críticas e interdisciplinares [...]. (BELLONI, 2005, p. 9, grifo meu).

É uma proposta curricular que tensiona a tradição pela qual os conhecimentos foram historicamente selecionados e distribuídos. Dessa forma, a educomunicação traz, em si, algumas questões bastante sensíveis e complexas, pois questiona a tradição e a forma como os conhecimentos não-oficiais foram sendo excluídos e marginalizados do currículo. Traz, portanto, à cena, a "luta pelo controle do significado" (APPLE, 1997, 2002).

Com as abordagens apresentadas, que delineiam as principais linhas de força em relação ao currículo para o trabalho com mídia-educação, parece ficar evidente a relação entre "educomunicação" ou "mídia-educação" ou "educação/comunicação" e os estudos críticos do currículo, principalmente no que se referem ao trabalho com a leitura e com os textos numa perspectiva de desenvolvimento da "[...] capacidade de investigar e ir além das aparências e de questionar o senso comum” (APPLE 1995, p. 187). É uma ideia 
de trabalho com texto muito próxima também às considerações de Freire em A importância do ato de ler (1989), bem como às de Giroux (1986) no que se refere a uma pedagogia radical.

\section{Projeto alunos em rede - mídias escolares}

Elaborado em 2008 pela Secretaria Municipal de Educação de Porto Alegre (SMED), o projeto Alunos em Rede - Mídias Escolares tem como objetivo desenvolver práticas educomunicativas nas escolas municipais. Entre as mídias mencionadas no projeto (blog, TV, vídeo, fotografia), a rádio ocupa um lugar de destaque.

Conforme entrevista realizada com a assessoria da SMED responsável pelo projeto, a ideia surgiu com a experiência de um professor de história da educação básica que, em 2006, iniciou um projeto de rádio-poste (basicamente com veiculação de músicas) com os alunos durante os intervalos das aulas. A rádio era produzida ao vivo com apenas microfone e uma caixa de som, e o objetivo principal era diminuir a violência entre os alunos no período do recreio. No ano seguinte, o professor elaborou um projeto de oficinas de rádio para a escola, tendo a cessão de sua carga-horária para dedicar-se ao projeto. A partir disso, começou a trabalhar coma ideia de webrádio, em que os estudantes deveriam fazer roteiros, gravar programas, editar e, por fim, postar a produção num blog e, depois, veicular os programas gravados nos intervalos. A partir da experiência, o professor começa a levar seus alunos para cobrir eventos oficiais fora da escola, o que traz projeção política para a secretaria de educação e visibilidade para a iniciativa.

Em 2008, é construído um projeto para a Secretaria Municipal, 
explicitamente articulado à ideia de educomunicação, com referências aos trabalhos de Ismar Santos e ao projeto desenvolvido em São Paulo pela ECA-USP. Então, o projeto passa a fazer parte do Setor de Inclusão Digital. A ideia era fomentar e multiplicar ações em webrádio para toda a rede. Mas a participação das escolas não é obrigatória e ocorre da seguinte forma: as escolas do município podem oferecer, durante o ano, algumas oficinas ministradas por um professor da própria escola. Para isso, a instituição e o professor proponente devem encaminhar um projeto à Secretaria de Educação Básica da SMED. Quando um projeto de oficina está vinculado à comunicação, esse é encaminhado à assessoria do Alunos em Rede - Mídias Escolares. Sendo aprovado, o professor tem até $50 \%$ de sua carga horária cedida e recebe algumas orientações sobre como a mídia-educação, mais especificamente a webrádio, está sendo pensada e produzida no âmbito da secretaria. No entanto, não é destinado recurso algum, e a escola, dentro de sua gestão financeira, deve providenciar espaço e equipamentos. Muitas vezes, o projeto acaba sendo desenvolvido ou na biblioteca ou na sala de informática.

A formação inicial oferecida ao professor cujo projeto de rádio é aprovado contempla aspectos técnicos relacionados a equipamentos e softwares livres, bem como uma discussão sobre os seguintes formatos radiofônicos: a "vinheta", a "entrevista" e a "notícia”. A orientação fornecida tenta padronizar a produção desses formatos, como as vinhetas de apresentação dos alunos para cada peça sonora. Além disso, há orientações para a realização de programas já existentes e produzidos por outras escolas participantes do projeto, como o "A Galera Informa”, que consiste na produção de informes e notícias, o programa "A Galera Pergunta", que explo- 
ra o gênero entrevista e, por fim, o programa "Recreio", que consiste em seleções musicais a serem transmitidos nos intervalos, que é o mais produzido nas escolas. Para todos os programas, há formulários padronizados a serem preenchidos por professores e alunos no desenvolvimento do trabalho, conforme a pauta produzida nas oficinas ou de acordo com a lista de músicas escolhidas pelos alunos. Ou seja, orienta-se que sejam trabalhados todos os tipos de roteiro como forma de sistematização e organização da produção oral dos alunos por meio desses formulários. Embora haja conversas iniciais sobre os gêneros radiofônicos, a formação é direcionada muito mais sobre o formato e a padronização estética dos programas do que sobre os usos e sentidos sociais dos gêneros discursivos. Em relação ao conteúdo, não há orientações sistemáticas, mas é incentivada a cobertura dos eventos escolares. Há ainda a orientação para que os professores mantenham um blog como um canal onde sejam publicadas as produções, com link no blog do projeto Alunos em Rede. Orienta-se também, caso a internet da escola seja muito lenta - o que é uma realidade na rede -, que as produções sejam enviadas à secretaria de educação para serem disponibilizadas no próprio blog do projeto.

Entre os problemas relatados pela assessoria do Alunos em Rede, foram mencionados quatro fatores preponderantes: a dificuldade de os docentes "lidarem" com a tecnologia; a incompreensão sobre a educomunicação; a resistência dos profissionais às ações e orientações vindas da Secretaria de Educação e, por fim, os discursos dos professores sobre a péssima qualidade dos equipamentos ou da conectividade à internet.

Desde sua implementação, o projeto contou com a participação de trinta escolas, mas não há dados oficiais sobre o número 
total de alunos, nem há avaliação sistemática sobre o projeto que revele, com precisão, as ações educomunicativas para além da produção dos programas e as causas que levaram algumas oficinas a não concluírem o trabalho. Em 2012, dez escolas iniciaram projeto relacionado à rádio, mas somente poucas obtiveram os resultados esperados, com produção sistemática de programas, veiculados na hora do intervalo das aulas e/ou postados em blog da escola ou do projeto. Do universo de escolas, foram selecionadas três para o estudo de caso. A seguir, são apresentados alguns dados sobre a experiência em educomunicação em uma das instituições que, ao ter seu projeto aprovado, passou a integrar o Alunos em RedeMídias Escolares. As informações foram obtidas por meio de entrevistas semiestruturadas, de observações, de análise do projeto do professor submetido à SMED, bem como pela análise do projeto político-pedagógico da escola. Por uma questão ética, os nomes da escola, dos professores e dos alunos não serão revelados.

\section{Reflexões sobre as experiências em educomunicação em uma escola no âmbito do projeto alunos em rede - mídias escolares}

A escola analisada neste artigo foi fundada no final da década de 1980. A comunidade escolar, de acordo com pesquisa realizada em 2008 para a construção do projeto político pedagógico da instituição (PPP), era formada por classes populares, em que $60 \%$ dos pais e alunos entrevistados não haviam concluído o ensino fundamental e apenas $2 \%$ tinham ensino superior incompleto. Segundo o PPP, a ocupação profissional das famílias pesquisadas exige pouca instrução formal: empregada doméstica, diarista, pin- 
tor, vigilante, marceneiro, porteiro, entre outras. Neste universo, a escola repensa seu lugar e reorganiza seu projeto pedagógico, em que o currículo é concebido, pelo menos textualmente e discursivamente, para conectar-se ao contexto social dos estudantes ao mesmo tempo em que visa socializar o saber sistematizado. Percebe-se, no texto do PPP, uma forte referência à educação crítica, afirmando-se que a escola deve, ao distribuir o conhecimento considerado como legítimo, organizar-se em um projeto emancipador, rompendo a hegemonia do saber dominante. Além das aulas regulares, a instituição oferece várias oficinas de aprendizagem nos contraturnos, por meio de programas federais, municipais e, inclusive, em parceria com instituições privadas, como o Clube de Futebol Internacional. Há oficinas de reforço escolar (letramento e matemática), de informática, de judô, de educação ambiental e, por fim, de webrádio.

O responsável pelo projeto é um professor de matemática que divide suas horas entre a sala de aula, a oficina de robótica e a oficina de rádio. Essa última já existia há dois anos na escola, mas somente agora passa a ser responsável, mediante projeto encaminhado à SMED. O objetivo do projeto é desenvolver um olhar crítico em relação à produção e ao conteúdo veiculado nas rádios e tornar os alunos produtores de conteúdo. Outros objetivos são desenvolver a linguagem oral e escrita, bem como as habilidades relacionadas à produção, como realização de pesquisas de conteúdo de forma autônoma e o uso de softwares de gravação e edição. Ao ser indagado sobre a relação entre seu projeto e o projeto Alunos em Rede - Mídias Escolares, informa que não recebeu formação sobre o trabalho com mídia-educação, apenas sobre alguns formatos e formulários que poderiam ser sistematizados para o 
trabalho pedagógico com mídia. Diz que uma das principais dificuldades é a demora na manutenção dos computadores e internet lenta para a postagem dos programas no blog. Relata não conhecer o termo educomunicação, embora afirme ter uma noção do que possa significar. Diz não conhecer as teorias ou reflexões acerca dos gêneros discursivos e não desenvolve o trabalho em metalinguagem, embora afirme ter discutido com os alunos - oito ao total -, no início da oficina, os formatos de notícia e entrevista.

Nas observações realizadas, o número de participantes oscilava entre dois e quatro alunos, com quatorze e quinze anos de idade, todos com acesso a celulares, possuindo computadores e internet em seus domicílios. Na oficina, foi constatado que as pautas produzidas pelos alunos coincidiam com o calendário escolar, como o "dia da criança" ou "festa junina", e os temas eram propostos pelo professor e não pelos alunos, não havendo uma discussão mais aprofundada sobre eles. No período de observação, os estudantes estavam produzindo o programa "A Galera Informa”, cujo tema era o Acampamento Farroupilha4, e o "Recreio", com organização das músicas para o tempo do intervalo e gravação de locução de créditos musicais. A seguir, descreverei algumas ações pedagógicas no processo de produção daquele programa.

No processo de produção do "A Galera Informa”, a partir da pauta colocada pelo professor, os alunos tinham a liberdade de produzir "matérias" sobre alguns ícones relacionados à cultura gaúcha, como as expressões linguísticas da zona rural, as comidas típicas do Sul e a história da Revolução Farroupilha. Os alunos buscavam textos na internet sobre os temas e deveriam fazer uma síntese de aspectos que considerassem interessantes de reportar. A síntese realizada acabava sendo uma colagem de vários trechos de diferentes textos e sites. $\mathrm{O}$ 
professor, então, insistia na ideia de se fazer referência a fontes e auxiliava os estudantes no processo de seleção de informações, indagando sobre a relevância ou não dos textos selecionados. Os alunos, por fim, copiavam os segmentos que seriam lidos na futura gravação dos programas. Nos encontros subsequentes, o professor auxiliava no uso do software livre utilizado para gravação e edição das peças sonoras, embora os alunos já demonstrassem autonomia nesse processo mais técnico. Na produção do programa "A Galera Informa", não foi promovida nenhuma discussão sobre as representações sociais do gaúcho, tampouco sobre o gênero notícia ou reportagem. Não foram problematizados nem a composição nem os aspectos discursivos e ideológicos dos textos que os alunos selecionaram. A oficina também não contemplou a audição de outras peças sonoras ou visuais sobre o tema com o intuito de fazer uma leitura crítica da mídia, já que o Acampamento Farroupilha é um tema bastante abordado pela imprensa local. Durante o processo da oficina, algumas conversas entre alunos e entre esses e o professor aconteciam de forma bastante descontraída. Falou-se de preferências alimentares, da cultura religiosa de cada um, como o candomblé, e de relacionamentos conjugais - havia uma adolescente casada (informalmente, pois tinha menos de dezoito anos). Ficou evidente que a cultura da comunidade era tema mais importante de ser pautado nas interações. Ao serem questionados sobre as pautas contempladas na oficina, os alunos confirmaram que os temas da comunidade não eram discutidos e o que se produzia na oficina eram programas sobre os eventos da própria escola ou temas que o professor escolhia, como o tema do Acampamento Farroupilha. Feito esse relato, passo a tecer algumas considerações sobre a cena observada e o projeto educomunicativo Alunos em Rede - Mídias Escolares. 


\section{Considerações finais}

Com o breve relato da produção do programa "A Galera Informa" em uma escola municipal de Porto Alegre, fica evidente o descompasso entre os objetivos do projeto da escola como do projeto Alunos em Rede - Mídias Escolares. Percebe-se que a oficina, embora tenha potencial para ser um espaço mais democrático, acaba constituindo-se como um lugar de reprodução de velhas práticas pedagógicas e discursos hegemônicos. No caso analisado, embora os alunos e professor estejam imersos na "cultura gaúcha", que é permeada pelo discurso tradicionalista, o trabalho apenas reforça os velhos estereótipos e os discursos sobre o que é ser, e não ser, gaúcho. O Acampamento Farroupilha reacende, a cada ano, uma pauta tradicionalista que é sexista, homofóbica, separatista, que silencia grupos sociais contrários ao consumo de carne e à pecuária. Mas a oficina fica indiferente a isso.

Um currículo em educomunicação, como mencionado nas seções anteriores, colocaria em pauta, no caso analisado, os vários discursos relacionados à construção da identidade regional e nacional. Poderia, ainda, problematizar os conteúdos produzidos pela imprensa, vinculando o tema às questões comunitárias, como o acesso (ou não) à carne e à comida, discutindo trabalho, remuneração, exploração e a fome que ainda é uma realidade no Brasil. Poderia ainda ser proposta uma pauta mais ampla de ação-comunicação, como a construção de hortas urbanas na escola e na comunidade, entre muitas outras passíveis de serem pensadas.

Percebe-se também que a oficina em educomunicação seria um espaço privilegiado para a realização do que é preconizado pelo PPP da escola, mas não é o que ocorre no caso analisado. A cultura e saberes comunitários não ganham espaço na produção radio- 
fônica, aparecendo somente, de forma não problematizada, nas conversas informais. Embora a assessoria da SMED afirme, como mencionado na seção anterior, que um dos problemas na implementação do projeto seja o pouco entendimento dos professores sobre a educomunicação, tampouco se evidencia, conforme relato do professor da escola analisada, um esforço da secretaria em promover formação mais ampla sobre a questão.

A partir do caso analisado, é pertinente pensar no conceito de tradição seletiva. Raymond Williams (1976 apud APPLE, 2006), ao analisar os processos pelos quais a hegemonia de um determinado grupo social é estabelecida, discute o papel das instituições sociais responsáveis pela transmissão cultural, como a escola. Nesse sentido, o autor define tradição seletiva como um processo que,

[...] nos termos de um cultura efetivamente dominante, é sempre passado como 'a tradição', $o$ passado significativo. Entretanto, a questão é sempre a seletividade; a maneira pela qual, de toda uma área possível do passado e do presente, somente determinados significados e práticas são escolhidos para ênfase, enquanto outros significados e práticas são negados e excluídos. (WILLIAMS, 1976, p. 205 apud APPLE, 2006, p. 39).

Ainda segundo Apple (op. cit., p. 103),

[...] pelo fato de preservarem e distribuírem o que se percebe como "conhecimento legítimo" - o conhecimento que 'todos devemos ter' -, que as escolas conferem legitimidade cultural ao conhecimento de determinados grupos.

Como a construção de uma oficina em webrádio não goza de uma tradição disciplinar como outras áreas do conhecimento, a tradição é recriada por meio de um calendário compartilhado e 
inquestionável pelos membros da comunidade escolar, silenciando as demandas dos grupos com quem a escola trabalha.

No período das observações, a pauta "Acampamento Farroupilha" não propiciou, nos termos de Orofino (2005), a construção de visibilidades, nem produziu respostas sociais sobre as questões subjacentes ao próprio acampamento e aos discursos que se organizam em torno dele.

Retomando algumas orientações propostas pelo termo "educomunicação", o qual está atrelado às ideias de Freire e Kaplún, percebe-se que a experiência analisada não permite nem uma problematização da mídia, nem propõe a construção de espaços mais democráticos no que se refere à construção das pautas, por exemplo. Em relação às aprendizagens proporcionadas pela construção da webrádio, dá-se prioridade ao ensino e manuseio livre do software, mas com padronização de textos e formatos.

Portanto, o trabalho, na oficina, por meio da bricolagem ingênua de textos e na sua tradução sonora pelos alunos, produz um pronunciamento mudo do mundo. Dessa forma, o projeto em sala de aula distancia-se da tradição crítica da comunicação alternativa e participativa - que culminou na formulação da educomunicação - e institui uma pedagogia instrumental dos meios.

\section{REFERENNCIAS}

APPLE, Michael W. Trabalho Docente e Textos: economia política das relações de classe de gênero em educação. Porto Alegre: Artes Médica, 1995.

- Conhecimento oficial: a educação democrática numa era conservadora. Petrópolis, RJ: Vozes, 1997. . Educação e Poder. Porto Alegre: ArtMed, 2002. 
. Ideologia e Currículo. 3. ed. Porto Alegre: ArtMed, 2006.

BRASIL. Ministério da Educação. Secretaria de Educação Continuada, Alfabetização e Diversidade. Programa Mais Educação Passo a Passo. Brasília, DF, [s.d.]. Disponível em: <http://portal.mec.gov.br/ dmdocuments/passoapasso_maiseducacao.pdf >. Acesso em: fev. 2012.

- Ministério da Educação. Secretaria de Educação Básica. Diretoria de Currículos e Educação Integral. Coordenação Geral do Ensino Médio. Programa Ensino Médio Inovador - Documento Orientador. Brasílica, DF, 2011.

BELLONI, Maria Luiza. O que é mídia-educação. Campinas, SP: Autores Associados, 2005.

CAPRINO, Mônica Pegurer. Interfaces Jornal e Educação: Panorama e Transformações na Sociedade Global. Intercom - Sociedade Brasileira de Estudos Interdisciplinares da Comunicação. In: XXXI CONGRESSO BRASILEIRO DE CIÊNCIAS DA COMUNICAÇÃO - Natal, RN - 2 a 6 de setembro de 2008. Anais... Disponível em: <http://www.intercom. org.br/papers/nacionais/2008/resumos/R3-1737-2.pdf >. Acesso em: nov. 2009.

CARNICEL, Amarildo. O jornal comunitário e a educação não-formal: experiências e reflexões. In: FUSER, Bruno (Org.). Comunicação Alternativa, cenários e perspectivas. Campinas: PUC-Campinas, Centro de Memória da UNICAMP, 2005.

FONSECA, Claúdia Chaves. Os meios de comunicação vão à escola? Belo Horizonte: Autêntica/FCH-FUMEC, 2004.

FREIRE, Paulo. A importância do ato de ler. São Paulo: Cortez, 1989.

GONNET, Jacques. Educação e mídias. São Paulo: Loyola, 2004.

GIROUX, Henry. Teoria crítica e resistência em educação: para além das teorias de reprodução. Rio de Janeiro: Vozes, 1986.

KAPLÚN, Mario. Comunicación entre grupos: el método del Cassete- 
Foro. Buenos Aires: Humanitas, 1988.

. Una pedagogía de la comunicación. Madrid: La Torre, 1998.

KAPLÚN, Gabriel. Kaplún, intelectual orgânico: memória afetiva. In: MELO, José Marques de; FERRARI, Maria Aparecida; NETO, Elydio dos Santos et. al. (Org.). Educomídia - Alavanca da Cidadania: o legado utópico de Mario Kaplún. São Bernardo do Campo, SP: Cátedra UNESCO: Universidade Metodista de São Paulo, 2005.

KELLNER, Douglas; SHARE, Jeff. A mídia-educação crítica e a democracia radical. In: APPLE, Michael W.; AU, Wayne; GANDIN, Luís Armando (Orgs.). Educação Crítica: análise internacional. Porto Alegre: Artmed, 2011. p. 315-330.

OROFINO, Maria Isabel. Mídias e mediação escolar: pedagogia dos meios, participação e visibilidade. São Paulo: Cortez: Instituto Paulo Freire, 2005.

PAIVA, Raquel (Org.). O Retorno da Comunidade: os novos caminhos do social. Rio de Janeiro: Mauad, 2007.

PERUZZO, Cicilia M. K. Revisitando os conceitos de comunicação popular, alternativa e comunitária. In: CONGRESSO BRASILEIRO DE CIÊNCIAS DA COMUNICAÇÃO, 29., 2006, Brasília. Anais... São Paulo: Intercom, 2006. 1 CD-ROM.

SCHAUN, Angela. Educomunicação: reflexões e princípios. Rio de Janeiro: Mauad, 2002.

SOARES, Ismar. Gestão Comunicativa e Educação: Caminhos da Educomunicação. Comunicação e Educação, São Paulo, n. 23, p. 16-25, jan./abr. 2002.

SOARES, Ismar. Educom. Rádio, na trilha de Mario Kaplún. In: MELO, José Marques de; FERRARI, Maria Aparecida; NETO, Elydio dos Santos et al. (Orgs.). Educomídia, alavanca da cidadania: o legado utópico de Mario Kaplún. São Bernardo do Campo: Cátedra Unesco, Universidade Metodista de São Paulo, 2006. 
TOTH, Mariann; MERTENS, Frédéric; MAKIUCHI, Maria de Fátima Rodrigues. Novos espaços de participação social no contexto do desenvolvimento sustentável: as contribuições da educomunicação. Ambiente e Sociedade [online], v. 15, n. 2, p. 113-132, 2012. ISSN 18094422.

TRESCA, Laura. Políticas Locais de Fomento à Comunicação Comunitária: os casos das prefeituras de Fortaleza, João Pessoa, Macapá, Porto Alegre e Recife. 2008. Dissertação (Mestrado em Comunicação Social) - Programa de Pós-Graduação em Comunicação Social, Universidade Metodista de São Paulo, 2008.

UNESCO. Media and Information Literacy: Curriculum for Teachers. Paris: UNESCO, 2011.

\section{Notas}

* Graduado em Letras - Língua Portuguesa e Literatura (UFRGS) e mestrando em Educação pela mesma universidade. Desde 2007, desenvolve projetos de comunicação comunitária para prefeituras e ONGs. É editor de conteúdo para Artmed/Grupo A. E-mail: <rodrigoramos.net@gmail.com>.

${ }^{1}$ Cabe mencionar que os princípios educativos do pedagogo subjazem as práticas formativas do Centro de Ligação do Ensino e Meios de Informação (CLEMI), fundado na década de 1980. Além de incentivar o uso de mídias no espaço escolar, oferecendo formação na área por meio de cursos e oficinas, o CLEMI também funciona como um memorial das mídias produzidas pelas escolas, que conta com um acervo de 65 mil jornais escolares (CAPRINO, 2008). O site do Centro é <www.clemi.org $>$.

${ }^{2}$ É interessante mencionar a distinção entre mídia educativa e educação midiática. A primeira atrela-se a programas de cunho pedagógico produzidos por grandes emissoras de rádio, televisão ou jornal, com vistas a formar o ouvinte, espectador ou leitor. Já a educação midiática envolve inúmeras ações, desde a leitura (crítica) de jornais à produção de vídeo pelos aprendizes, com vistas a discutir e refletir sobre um tema específico.

${ }^{3}$ Disponível em: $<$ http://www.revistacomunicar.com/index.php?contenido=re vista\&numero $=32>$.

${ }^{4}$ Em Porto Alegre, há alguns anos, os Centros de Tradições Gaúchas (CTGs), em comemoração à chamada Revolução Farroupilha, organizam, durante uma semana, um acampamento no parque Harmonia, na orla do lago Guaíba, ponto turístico e espaço de lazer da capital gaúcha. 